\title{
Clinical and biological significance of transcription termination factor, RNA polymerase I in human liver hepatocellular carcinoma
}

\author{
HISATERU KOMATSU ${ }^{1,2}$, TOMOHIRO IGUCHI ${ }^{1}$, MASAMI UEDA ${ }^{1}$, SHO NAMBARA $^{1}$, TOMOKO SAITO ${ }^{1}$, \\ HIDENARI HIRATA $^{1}$, SHOTARO SAKIMURA ${ }^{1}$, YUKI TAKANO ${ }^{1}$, RYUTARO UCHI ${ }^{1}$, YOSHIAKI SHINDEN ${ }^{1}$, \\ HIDETOSHI EGUCHI $^{1}$, TAKAAKI MASUDA ${ }^{1}$, KEISHI SUGIMACHI ${ }^{1}$, HIDETOSHI EGUCHI ${ }^{2}$ \\ YUICHIRO DOKI $^{2}$, MASAKI MORI $^{2}$ and KOSHI MIMORI ${ }^{1}$ \\ ${ }^{1}$ Department of Surgery, Kyushu University, Beppu Hospital, Beppu, Oita; \\ ${ }^{2}$ Department of Gastroenterological Surgery, Graduate School of Medicine, Suita, Osaka, Japan
}

Received July 13, 2015; Accepted December 4, 2015

DOI: $10.3892 /$ or.2016.4593

\begin{abstract}
Recent studies have indicated that increased ribosomal activity contributes to cancer progression. Transcription termination factor, RNA polymerase I (TTF1) acts as a transcription factor for RNA polymerase I. However, the role which TTF1 plays in cancer progression still remains unknown. The present study aimed to determine whether TTF1 plays a critical role in the progression of human liver hepatocellular carcinoma (HCC). In the present study, quantitative real-time reverse transcription polymerase chain reaction was conducted to evaluate TTF1 mRNA expression in $60 \mathrm{HCC}$ tissue samples in order to determine the clinicopathological significance of TTF1. To investigate whether the expression levels of TTF1 were associated known gene signatures which represented ribosomal activity, we applied gene set enrichment analysis (GSEA) to HCC cases in The Cancer Genome Atlas (TCGA) a. We also performed in vitro proliferation assays using TTF1-overexpressing HCC cells. TTF1 expression was significantly higher in HCC tumor tissues than in adjacent liver tissues $(\mathrm{P}<0.001)$. The overall survival $(\mathrm{OS})$ of patients with high TTF1 expression levels was significantly shorter than that of patients with low TTF1 expression $(\mathrm{P}=0.027)$. Multivariate analysis indicated that TTF1 expression was an independent prognostic factor for $\mathrm{OS}(\mathrm{P}=0.020)$. GSEA revealed significant associations between TTF1 expression and gene sets involved in ribosomal function. In vitro, cell proliferation and rRNA transcription were significantly promoted by overexpression of TTF1 in the HCC cell lines HuH-7 and HepG2. From these
\end{abstract}

Correspondence to: Professor Koshi Mimori, Department of Surgery, Kyushu University, Beppu Hospital, 4546 Tsurumihara, Beppu 874-0838, Oita, Japan

E-mail:kmimori@beppu.kyushu-u.ac.jp

Key words: transcription termination factor, RNA polymerase I, hepatocellular carcinoma, ribosome, biomarker, cancer progression results, it was suggested that TTF1 participate in poor prognoses and play a role in tumor cell growth in $\mathrm{HCC}$, possibly by upregulating ribosomal activity. In conclusion, we first propose that TTF1 may be a novel biomarker and therapeutic target in HCC. Increased expression of TTF1 was significantly associated with poor prognosis in two independent sets of HCC cases. Furthermore, in vitro experiments provided an explanation for clinical data showing that overexpression of TTF 1 contributed to the proliferation of cancer cells.

\section{Introduction}

Liver cancer is one of the most common malignancies and is the second and sixth most frequent cause of cancer-related death in men and women, respectively (1). Among primary liver cancers, hepatocellular carcinoma (HCC) represents the major histological subtype, accounting for $70-85 \%$ of the total liver cancer burden worldwide (2). Therefore, identification of novel clinical biomarkers and molecules contributing to tumor progression in $\mathrm{HCC}$ is critically required.

One of the main functions of ribosomes is translation of mRNA to protein, and cancer cells generally exhibit increased ribosomal synthesis $(3,4)$. Ribosomes consist of ribosomal proteins and ribosomal RNA (rRNA) molecules (5), and the biogenesis of ribosomes requires the coordinated actions of all three DNA-dependent RNA polymerases (Pol I, II and III) $(6,7)$. Transcription termination factor, RNA polymerase I (TTF1) is a protein encoded by the TTF1 gene at 9q34.13; this protein mediates rRNA gene activation or silencing (8) and is essential for ribosome biogenesis (9). TTF1 can bind to multiple sites both downstream and upstream of rRNA genes (10-12), and TTF1 binding to the upstream proximal promoter sites of rRNA genes activates their transcription, while TTF1 binding to sites downstream of rRNA genes is related to termination of transcription $(13,14)$. Excessive ribosome biogenesis and translation initiation lead to tumor progression in HCC (15). Since cancer cells exhibit increased ribosomal activity and since TTF1 is closely associated with ribosomal activity, TTF1 may have clinical or biological importance in cancer. 
However, the significance of TTF1 in solid cancer has not been fully investigated. In the present study, we investigated the clinicopathological significance of aberrant TTF1 expression in HCC cases. In order to validate the clinical significance of TTF1 in the public database, we also performed gene set enrichment analysis (GSEA) and assessed whether the levels of TTF1 expression were associated with the unfavorable prognostic signature in HCC. Finally, we examined the capacity for TTF1-dependent HCC cell proliferation to provide an explanation for clinical data in vitro.

\section{Materials and methods}

Patients and sample collection. Sixty patients with HCC who underwent hepatic resection at Kyushu University Beppu Hospital and Affiliated Hospitals between 2001 and 2004 were enrolled in the present study. Resected HCC tumor and paired adjacent liver tissues were immediately frozen in liquid nitrogen and kept at $-80^{\circ} \mathrm{C}$ until RNA extraction. An intermittent follow-up was conducted after the operation, and the average follow-up period for the 60 patients was 70.1 months (range, 1.7-138.8 months). All protocols were approved by the Ethics and Indications Committee of Kyushu University. Written informed consent was obtained from all the patients.

Cell lines. Human HCC cells (HuH-7 and HepG2) were provided by the Cell Resource Center for Biomedical Research (Institute of Development, Aging and Cancer, Tohoku University, Japan). Cell lines were maintained in Dulbecco's modified Eagle's medium (DMEM; Gibco, Carlsbad, CA, USA) supplemented with $10 \%$ fetal calf serum and antibiotics. All cells were cultured at $37^{\circ} \mathrm{C}$ in a humidified atmosphere containing $5 \% \mathrm{CO}_{2}$.

Cloning of human TTF1 cDNA. To generate TTF1 expression lentiviral vectors, we amplified the insert (full-length human TTF1; NM_001205296.1) by polymerase chain reaction (PCR) from human reference cDNA. Transient transfections were performed using CSII-CMV-MCS (empty) plasmid DNAs (5'-BamHI and 3'-HpaI sites) and Lipofectamine 2,000 (Invitrogen, Carlsbad, CA, USA) according to the manufacturer's protocol.

$R N A$ preparation and reverse transcription $(R T)-P C R$. Total RNA from frozen tissue specimens and HCC cell lines was extracted using ISOGEN (Nippon Gene, Tokyo, Japan). The quality assessment of extracted RNA was performed by measuring absorbance, and we confirmed that all of them kept satisfactory quality. cDNA was synthesized from $8 \mu \mathrm{g}$ total RNA with M-MLV reverse transcriptase (Invitrogen).

Quantitative real-time PCR ( $q R T-P C R)$. Gene-specific oligonucleotide primers were designed for PCR. The following primers were used: $T T F 1,5$ '-GAAAGGTTGTATGAAATAA ATGTGGA-3' (sense) and 5'-TTGAACGTAAGATGGAGG AACA-3' (antisense); glyceraldehyde-3-phosphate dehydrogenase (GAPDH), 5'-TTGGTATCGTGGAAGGACTCA-3' (sense) and 5'-TGTCATCATATTTGGCAGGTT-3' (antisense); 28S ribosomal RNA, 5'-TTACCCTACTGATGATGTGTT GTTG-3' (sense) and 5'-CCTGCGGTTCCTCTCGTA-3' (anti- sense). PCR amplification was performed in a LightCycler 480 instrument using a LightCycler 480 Probes Master kit (both from Roche Applied Science Basel, Switzerland). mRNA amplification conditions consisted of initial denaturation at $95^{\circ} \mathrm{C}$ for $10 \mathrm{~min}$, followed by 40 cycles of denaturation at $95^{\circ} \mathrm{C}$ for $10 \mathrm{sec}$, annealing at $62^{\circ} \mathrm{C}\left(60^{\circ} \mathrm{C}\right.$ for some genes) for $10 \mathrm{sec}$, and elongation at $67^{\circ} \mathrm{C}\left(65^{\circ} \mathrm{C}\right.$ for some genes) for $10 \mathrm{sec}$. Melting curve analysis was performed to distinguish specific products from non-specific products and primer dimers. The relative expression levels of the gene were obtained by normalizing the amount of mRNA to that of GAPDH mRNA as an endogenous control in each sample.

Western blot analysis. Total protein was extracted from TTF1-expressing and mock-transfected cell lines. Aliquots of total protein $(40 \mu \mathrm{g})$ were electrophoresed on $10 \%$ polyacrylamide gels and then electroblotted on nitrocellulose membranes using Trans-Blot Transfer Medium (Bio-Rad Laboratories, Hercules, CA, USA) at $0.4 \mathrm{~A}$ for $120 \mathrm{~min}$. TTF1 protein was detected using rabbit polyclonal antibodies (ab87726; Abcam, Cambridge, UK) diluted 1:2,000. TTF1 protein levels were normalized to the level of $\beta$-actin protein, which was detected using monoclonal antibodies (Cytoskeleton Inc., Denver, CO, USA) at a 1:1,000 dilution. Blots were developed with horseradish peroxidase-linked anti-rabbit or anti-mouse immunoglobulin (Promega, Madison, WI, USA) diluted at 1:1,000. Enhanced chemiluminescence detection reagents (Amersham Biosciences, Piscataway, NJ, USA) were used to detect antigen-antibody reactions.

Immunohistochemical analysis. HCC tissues were surgically removed, embedded in paraffin and sectioned (5- $\mu \mathrm{m}$ sections). Immunohistochemical analysis was applied to determine the localization of TTF1. A polyclonal rabbit anti-TTF1 antibody (ab87726; 1:200; Abcam) was used as the primary antibody following the manufacturer's protocols.

Data extraction from public clinical dataset, copy number analysis, and GSEA. We obtained expression data of $371 \mathrm{HCC}$ cases and copy number data of 377 cases from The Cancer Genome Atlas (TCGA) from the Broad Institute's Firehose (http://gdac.broadinstitute.org/runs/stddata_2014_12_06/data/ LIHC/2014_12_06/). Expression profiles of TCGA dataset were analyzed by GSEA (16). Gene sets extracted from the Broad Institute database and the Uniform Resource Locator of their source are as follows. LEE_LIVER_CANCER_ SURVIVAL_DN (http:/www.broadinstitute.org/gsea/msigdb/ cards/LEE_LIVER_CANCER_SURVIVAL_DN.html), LEE_ LIVER_CANCER_SURVIVAL_UP (http://www.broadinstitute. org/gsea/msigdb/cards/LEE_LIVER_CANCER_SURVIVAL_ UP.html), RIBONUCLEOPROTEIN_COMPLEX (http:// www.broadinstitute.org/gsea/msigdb/cards/RIBONUCLEO PROTEIN_COMPLEX.html), STRUCTURAL_CONSTI TUENT_OF_RIBOSOME (http://www.broadinstitute. org/gsea/msigdb/cards/STRUCTURAL_CONSTITUENT_ OF_RIBOSOME.html), RIBONUCLEOPROTEIN_ COMPLEX_BIOGENESIS_AND_ASSEMBLY (http://www. broadinstitute.org/gsea/msigdb/cards/RIBONUCLEO PROTEIN_ COMPLEX_BIOGENESIS_AND_ASSEMBLY.html), PROTEIN_RNA_COMPLEX_ASSEMBLY (http://www. 
A
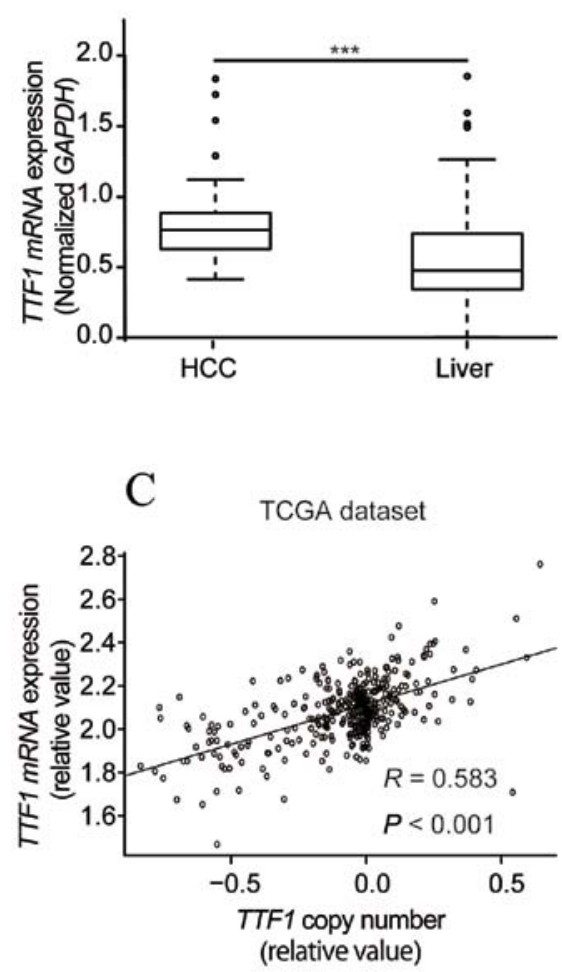

B

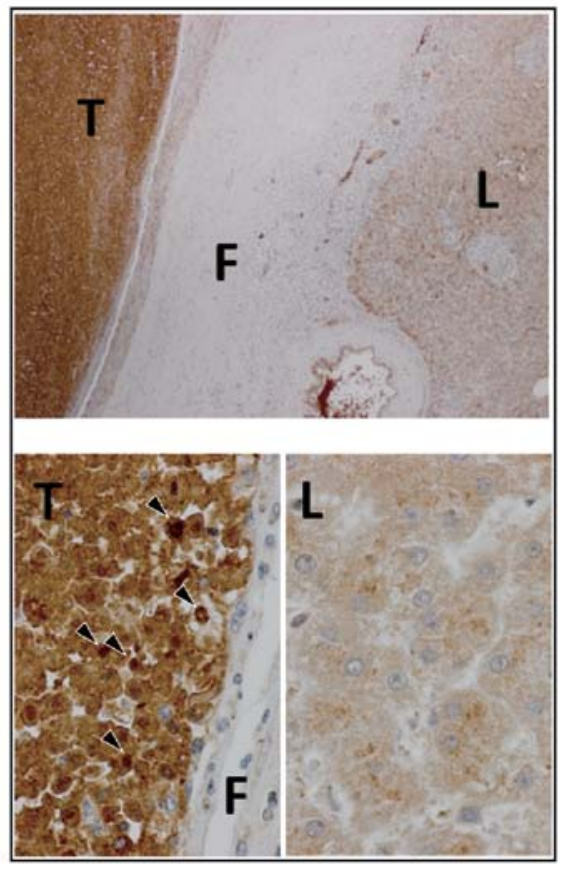

Figure 1. TTF1 mRNA and protein levels were upregulated in tumor tissues in HCC cases, and a strong correlation was observed between copy number and mRNA expression. (A) Comparison of TTF1 expression between tumor tissues and normal tissues in our cases as assessed by qRT-PCR normalized to GAPDH $\left({ }^{* * *} \mathrm{P}<0.001\right)$. (B) Immunohistochemistry of TTF1 expression in representative HCC samples; magnification, $\mathrm{x} 40$ (upper) and $\mathrm{x} 400$ (lower). T, tumor tissue; L, liver tissue; F, fibrous capsule. Arrowheads indicate stained TTF1 at nuclei. (C) Correlation analysis between TTF1 copy number and expression in TCGA dataset $(\mathrm{R}=0.583)$.

broadinstitute.org/gsea/msigdb/cards/PROTEIN_RNA_ COMPLEX_ASSEMBLY.html). We also acquired the expression profiles of TTF1 and the survival information in Gene Expression Omnibus database (accession code GSE14520) (17).

Cell proliferation assay. Twenty-four hours before the assay, cells were transfected with TTF1 cDNA or empty cDNA. 3-(4,5-Dimethylthiazol-2-yl)-2,5-diphenyltetrazolium bromide (MTT) assays were conducted to evaluate cell proliferation. First, $10 \mu \mathrm{l}$ of MTT-labeling reagent (final concentration, $0.5 \mathrm{mg} / \mathrm{ml}$ ) was added to each well, and the plate was incubated for $4 \mathrm{~h}$ in a humidified atmosphere. Next, solubilization solution $(100 \mu \mathrm{l})$ was added to each well, and the plate was incubated for $12 \mathrm{~h}$ in a humidified atmosphere. After confirming that the purple formazan crystals were completely solubilized, the absorbance of each well was measured using a Model 550 series microplate reader (Bio-Rad Laboratories) at a wavelength of $570 \mathrm{~nm}$ corrected to $655 \mathrm{~nm}$. The assay was performed using six replicates.

Statistical analysis. For continuous variables, data are expressed as means \pm standard deviations, and statistical analyses were performed using paired t-tests in comparisons between corresponding tumor and normal tissues. Other analyses were performed using Welch's t-tests. Categorical variables were compared using the Chi-square or Fisher's exact tests. Overall survival (OS) was estimated using the Kaplan-Meier method, and survival curves were compared using the log-rank test. Univariate and multivariate analysis was performed using the Cox regression model to identify independent variables predictive of OS. P-values of $<0.05$ were considered to indicate a statistically significant result. Data analyses of clinicopathological factors were performed using JMP 9 software (SAS Institute, Cary, NC, USA), and other analyses were performed using $\mathrm{R}$ version 3.1.1 (The R Foundation for Statistical Computing, Vienna, Austria).

\section{Results}

TTF1 mRNA and protein expression are upregulated in HCC tissues. To identify whether TTF1 was critical for HCC progression, we used qRT-PCR to examine TTF1 mRNA expression in 58 clinical paired tumor and normal tissues. TTF1 mRNA expression in cancerous tissues was significantly upregulated compared with that in the matched normal tissues $(\mathrm{P}<0.001$; Fig. 1A). Moreover, immunohistochemical analysis revealed that TTF1 protein levels were markedly higher in HCC tissues than in corresponding liver tissues (Fig. 1B). Staining in cytoplasm was observed in both HCC and liver tissues. In contrast, staining in nuclei was characteristically observed in tumor tissues.

TTF1 gene copy number analysis using the TCGA HCC dataset. To assess whether TTF1 gene copy number variations 
A Primary HCC cases

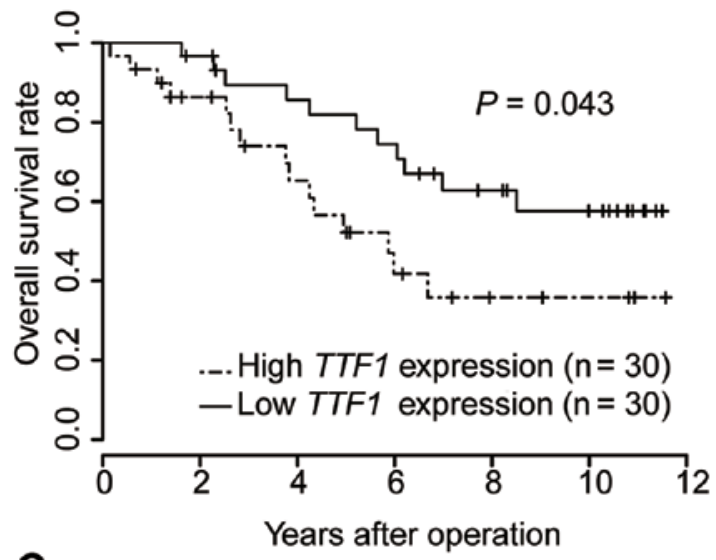

C

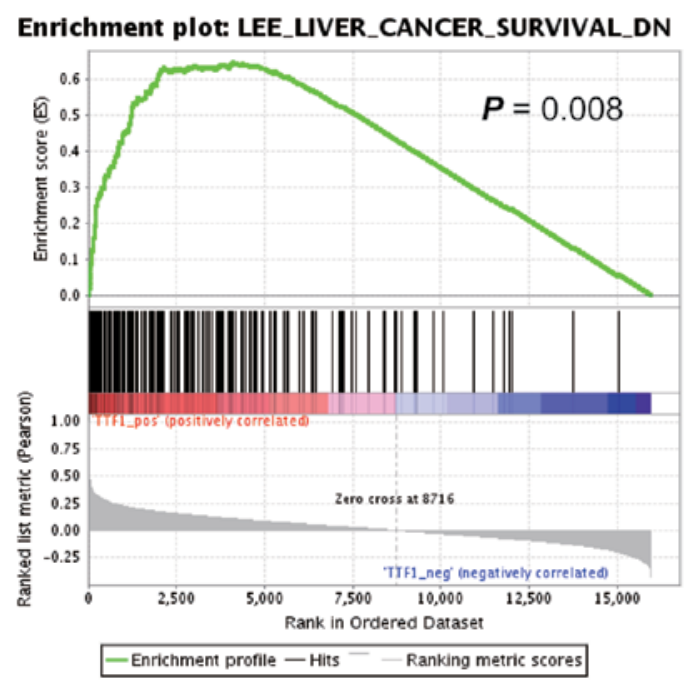

B

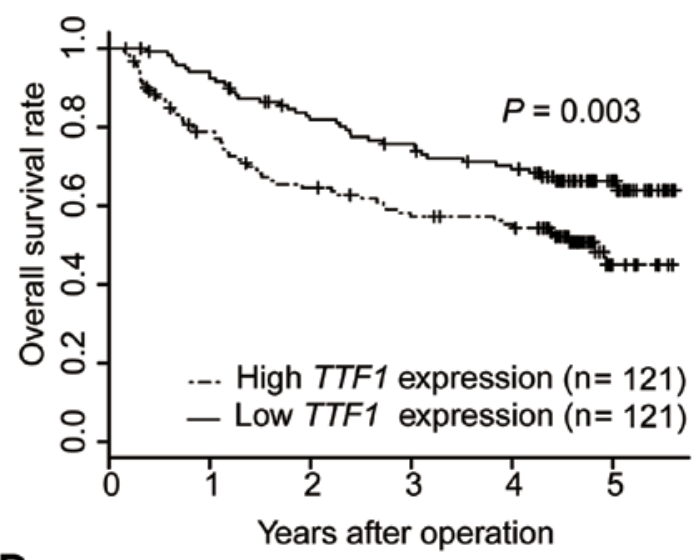

D

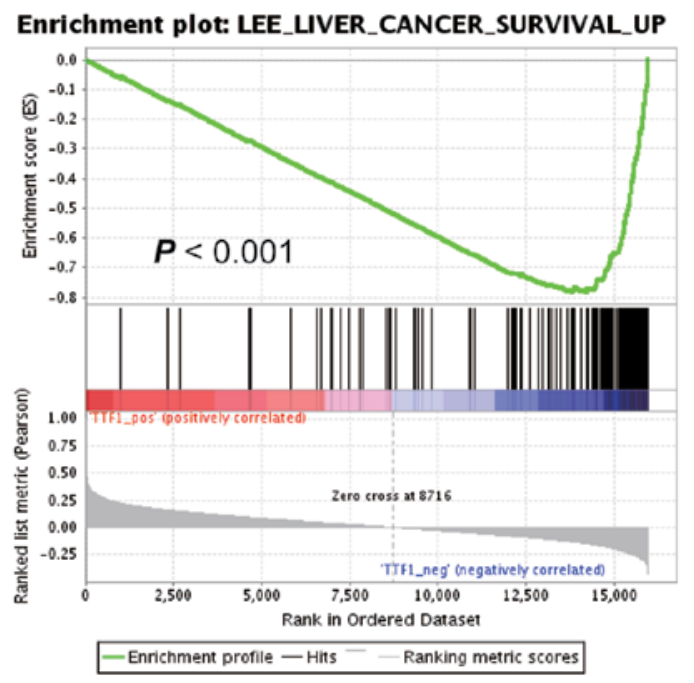

Figure 2. Increased expression of TTF1 in tumor tissue was associated with poor prognosis in HCC cases. (A) Overall survival curves of 60 HCC cases from our hospital ( $\mathrm{P}=0.027)$. (B) Overall survival curves of $242 \mathrm{HCC}$ cases from the GSE14520 dataset $(\mathrm{P}=0.003)$. (C and D) Correlations with published gene sets related to prognosis in TCGA dataset.

affected $T T F 1$ gene expression, we extracted copy number data from the TCGA dataset. A strong correlation between copy number and TTF1 expression was observed in tumor tissues $(\mathrm{R}=0.583, \mathrm{P}<0.001$; Fig. $1 \mathrm{C})$.

Increased expression of TTF1 is associated with poor prognosis in patients with $\mathrm{HCC}$. To estimate the clinical significance of TTF1 expression in HCC, TTF1 expression was analyzed by qRT-PCR in 60 samples from patients who underwent resection of primary HCC. According to TTF 1 expression level, cases were divided into two groups. Cut-off values were set at the median value of TTF1 mRNA expression. There were no significant differences in clinicopathological parameters between high and low TTF1 expression groups (data not shown). On univariate analysis, the OS rate of the high $T T F 1$ expression group was significantly lower than that of the low TTF1 expression group ( $\mathrm{P}=0.027$; Fig. 2A). Furthermore, multivariate analysis showed that high TTF1 expression was an independent prognostic factor for poorer OS (Table I; $\mathrm{P}=0.020$ ). We further analyzed OS for a public dataset of $242 \mathrm{HCC}$ cases from GSE14520 (17) to confirm the results of our series. In accordance with our data, the OS of the high $T T F 1$ expression group was significantly poorer than that of the low TTF1 expression group (Fig. 2B; $\mathrm{P}=0.003$ ).

GSEA using reference datasets. To investigate whether the expression levels of TTF1 were associated with known gene signatures, we applied GSEA to HCC cases from TCGA datasets. GSEA revealed that TTF1 expression levels positively correlated with an unfavorable prognostic gene signature (Fig. 2C) and negatively correlated with a signature representing favorable outcomes (Fig. 2D). Moreover, GSEA showed that TTF1 expression levels were significantly correlated with activity of gene sets which were involved in ribosomal function (Fig. 3A-D).

Overexpression of TTF1 enhances the transcription of $r R N A$ in human HCC cells. To explore the biological role of TTF1 in $\mathrm{HCC}$, we performed overexpression experiments in $\mathrm{HuH}-7$ and HepG2 cells. We confirmed that TTF1 mRNA and TTF1 protein expression was significantly higher in cells transfected with TTF1 cDNA than in cells transfected with empty 
Table I. Univariate and multivariate analyses of clinicopathological factors affecting overall survival in primary HCC cases $(n=60)$.

\begin{tabular}{|c|c|c|c|c|c|}
\hline \multirow[b]{2}{*}{ Variable } & \multirow[b]{2}{*}{ No. of patients } & \multicolumn{2}{|c|}{ Univariate analysis } & \multicolumn{2}{|c|}{ Multivariate analysis } \\
\hline & & OS $(\%)$ & P-value & Hazard ratio $(95 \% \mathrm{CI})$ & P-value \\
\hline Age (years) & & & 0.795 & & \\
\hline$>70$ & 28 & 57.1 & & & \\
\hline$\leq 70$ & 32 & 53.1 & & & \\
\hline Gender & & & 0.896 & & \\
\hline Male & 39 & 53.8 & & & \\
\hline Female & 21 & 57.1 & & & \\
\hline $\mathrm{HBV}$ & & & 0.483 & & \\
\hline$(+)$ & 12 & 75.0 & & & \\
\hline$(-)$ & 48 & 50.0 & & & \\
\hline $\mathrm{HCV}$ & & & 0.051 & & \\
\hline$(+)$ & 44 & 44.5 & & & \\
\hline$(-)$ & 16 & 81.3 & & & \\
\hline Child-Pugh & & & 0.350 & & \\
\hline A & 50 & 58.0 & & & \\
\hline B or C & 10 & 40.0 & & & \\
\hline Tumor size (cm) & & & 0.320 & & \\
\hline$>3$ & 29 & 48.4 & & & \\
\hline$\leq 3$ & 31 & 62.1 & & & \\
\hline No. of tumors & & & 0.006 & $3.06(1.40-6.52)$ & 0.002 \\
\hline Single & 42 & 64.3 & & & \\
\hline Multiple & 18 & 33.3 & & & \\
\hline fc & & & 0.744 & & \\
\hline$(+)$ & 43 & 53.5 & & & \\
\hline$(-)$ & 17 & 58.8 & & & \\
\hline $\mathrm{vp}$ & & & 0.890 & & \\
\hline$(+)$ & 33 & 54.5 & & & \\
\hline$(-)$ & 27 & 55.6 & & & \\
\hline $\mathrm{vv}^{\mathrm{a}}$ & & & 0.170 & & \\
\hline$(+)$ & 3 & 0.0 & & & \\
\hline$(-)$ & 56 & 57.1 & & & \\
\hline $\mathrm{b}$ & & & 0.019 & $60.5(2.39-1528)$ & 0.015 \\
\hline$(+)$ & 1 & 0.0 & & & \\
\hline$(-)$ & 59 & 55.9 & & & \\
\hline$T T F 1$ expression & & & 0.030 & $2.93(1.02-10.5)$ & 0.020 \\
\hline High & 30 & 46.6 & & & \\
\hline Low & 30 & 63.3 & & & \\
\hline
\end{tabular}

HCC, hepatocellular carcinoma; OS, overall survival; CI, confidential interval; HBV, hepatitis B virus; HCV, hepatitis C virus; fc, capsular formation; vp, invasion to portal vein; vv, venous invasion; b, invasion to bile duct. ${ }^{\text {Inf }}$ (normation on venous invasion was not available for one patient.

plasmid (Fig. 4A and B). Next, to confirm that upregulated expression of TTF1 contributed to the increased synthesis of rRNA in HCC cells, we performed quantitative analysis with qRT-PCR of 28S rRNA, which was one of the degradation products of $45 \mathrm{~S}$ rRNA and was reported to reflect the quantity of transcribed rRNA (18). As a result, overexpression of
TTF1 led to the increased expression of 28S rRNA, HuH-7 and HepG2 cells in comparison with mock-transfected cells (Fig. 4C; $\mathrm{P}=0.011$ and $\mathrm{P}<0.001$, respectively).

Ectopic TTFl enhances the growth of HCC cell lines. MTT assays were used to examine whether cell growth rates were 
A

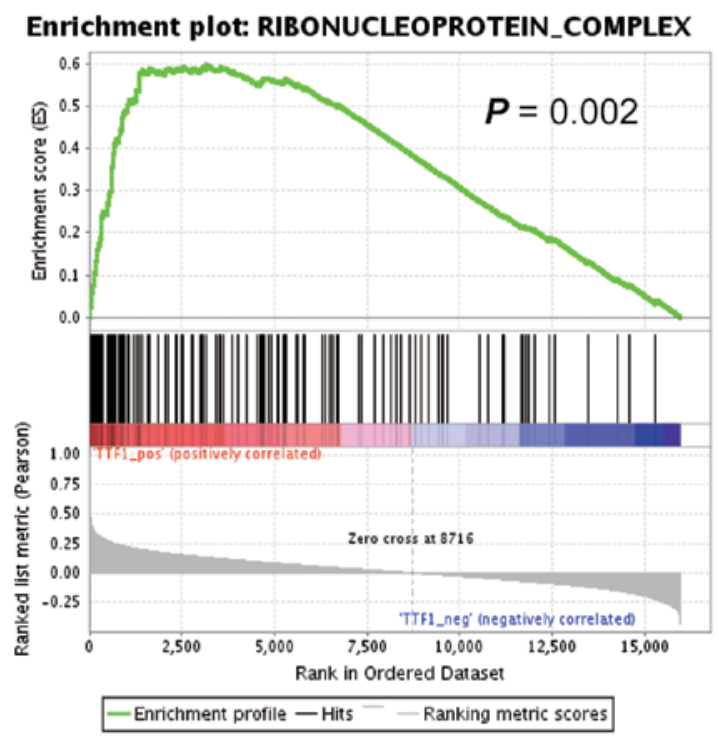

C

Enrichment plot: PROTEIN_RNA_COMPLEX_ASSEMBLY

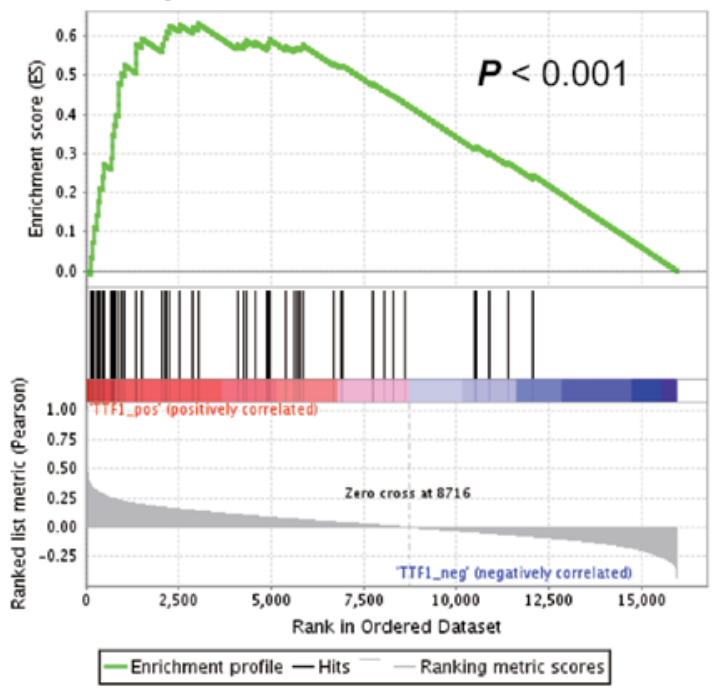

B

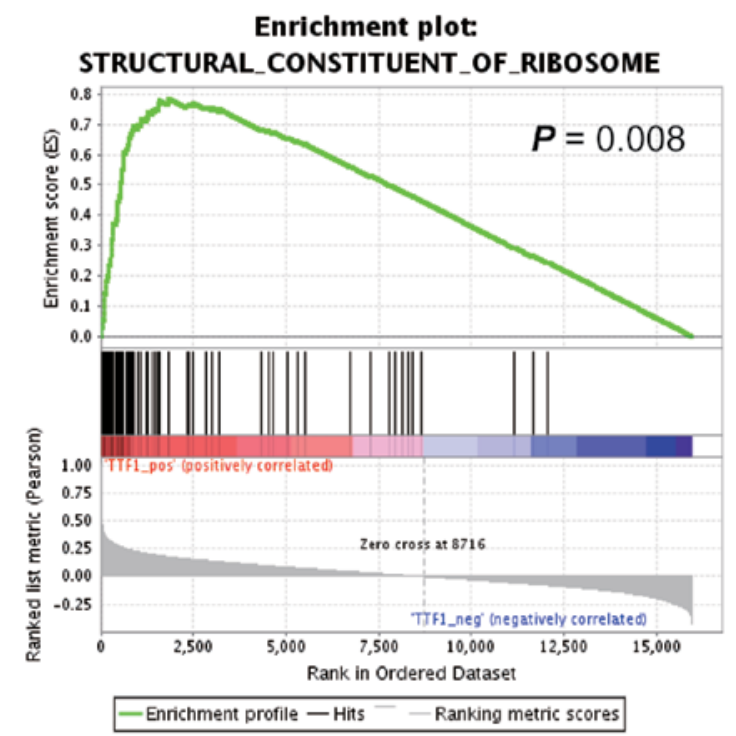

D
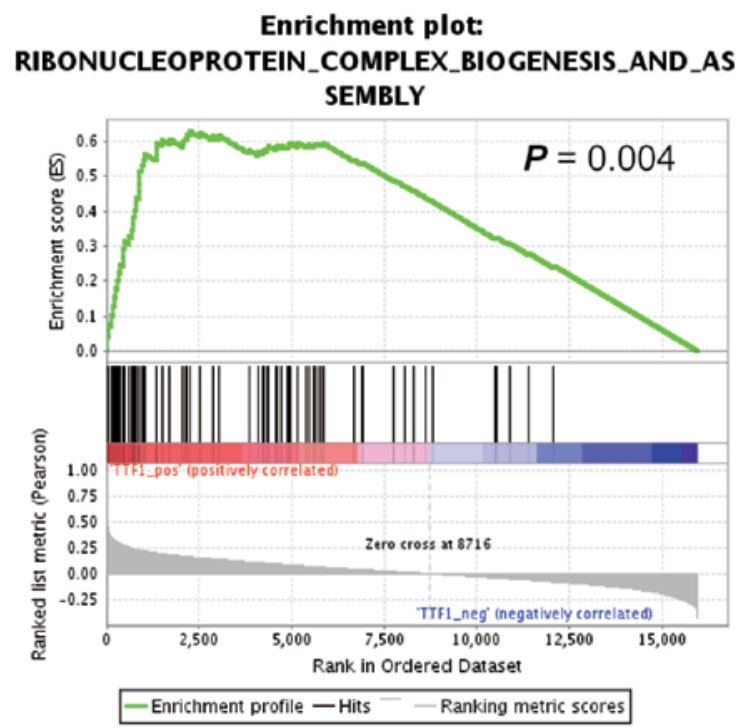

Figure 3. Gene sets related to ribosomal activity and prognostic factors were correlated with TTF1 expression in GSEA. (A-D) Correlations with gene sets related to ribosomal activity in TCGA dataset.

altered in cancer cells transfected with TTF1 cDNA. As a result, overexpression of $T T F 1$ promoted the proliferation of HuH-7 and HepG2 cells in comparison with mock-transfected cells (Fig. 5A and $\mathrm{B} ; \mathrm{P}=0.007$ and $\mathrm{P}=0.018$, respectively).

\section{Discussion}

It is well known that cancer cells frequently exhibit relatively high nucleolar activity and increased ribosome biogenesis, which contributes to cancer progression (19). TTF1 has been reported to mediate ribosomal activity through regulating the activation/silencing of rRNA $(13,14)$. However, the clinicopathological significance of TTF1 in solid cancers is not fully understood. In the present study, we showed the involvement of TTF1 in tumor progression of HCC.
First, we found that TTF1 mRNA and protein expression was high in HCC tissues as compared to that in corresponding normal tissues. Unlike adjacent liver tissues, localization of TTF1 protein in nuclei was observed in HCC tissues. This corresponds with previous studies that the nucleolus is the site of biosynthesis of ribosomal RNA (20), and that increase in number of nucleolus is observed in cancer cells (3). In cancer, copy number variation has been shown to influence gene expression (21). Consistent with this, we observed a strong correlation between copy number and TTF1 expression in tumor tissues. Hence, the intertumoral differences in TTF1 expression levels may be explained by copy number variations.

Next, we showed that higher expression of TTF1 predicted poor prognosis and was an independent prognostic factor for HCC. To provide an adequate explanation for clinical signifi- 
A

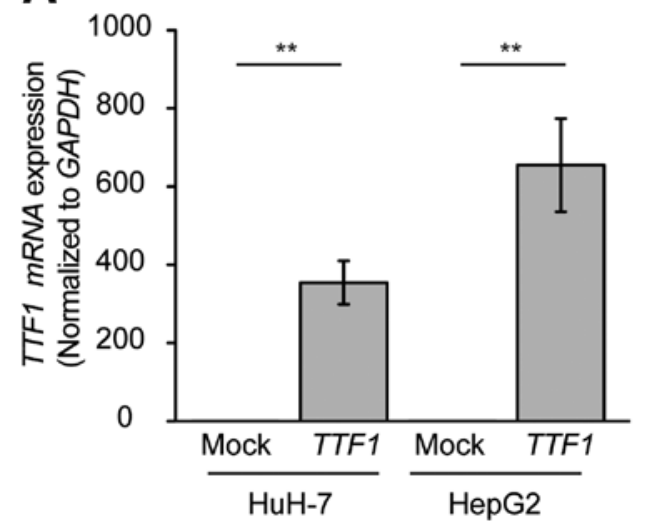

B

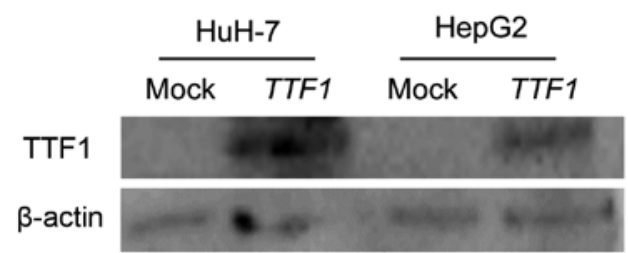

\section{C}

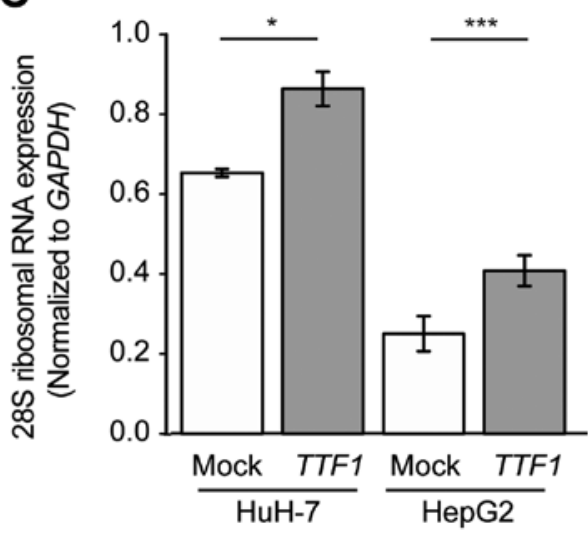

Figure 4. Overexpression of TTF1 enhances the transcription of rRNA in human HCC cells. (A) mRNA expression of TTF1 in mock-transfected or TTF1expressing HuH-7 and HepG2 cells measured by quantitative RT-PCR ( ${ }^{* *} \mathrm{P}<0.01$, both). (B) Western blot analysis of TTF1 protein levels in mock-transfected or TTF1-expressing HuH-7 and HepG2 cells. (C) Comparison of 28S rRNA expression between in mock-transfected or TTF1-expressing HuH-7 and HepG2 cells $\left(\right.$ P $\left.\mathrm{P}<0.05,{ }^{* * * *} \mathrm{P}<0.001\right)$.

A

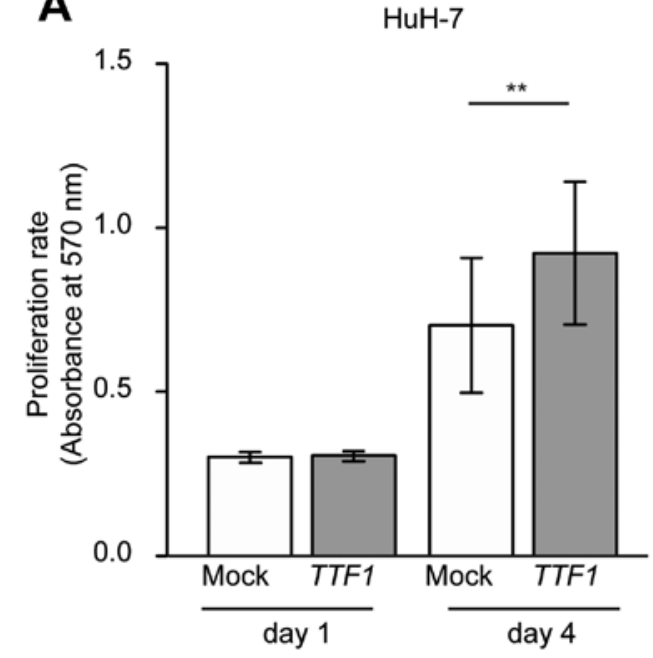

B

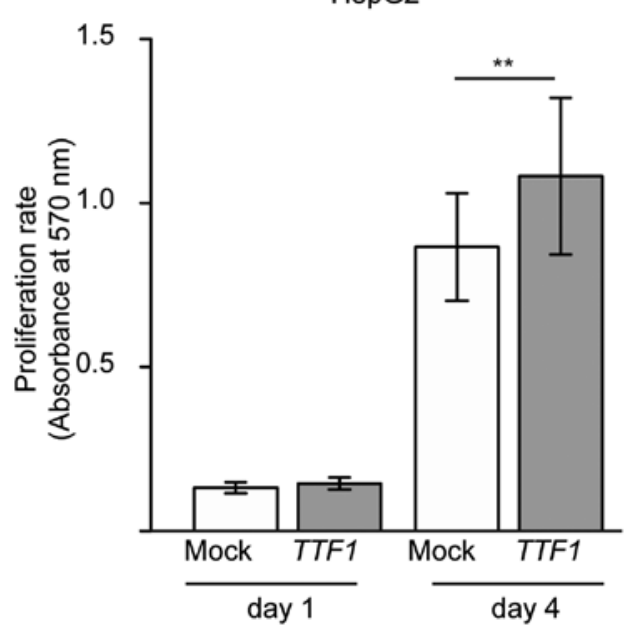

Figure 5. Overexpression of TTF1 by transfection with TTF1 cDNA enhanced the proliferation of human HCC cell (MTT assay). (A) Comparison of proliferation ratio between in mock-transfected or TTF1-expressing HuH-7 cells $\left({ }^{* *} \mathrm{P}<0.01\right)$. (B) Comparison of proliferation ratio between mock-transfected and TTF1-expressing HepG2 cells $\left({ }^{* *} \mathrm{P}<0.01\right)$.

cance, we interrogated the public databases. GSEA indicated that TTF1 mRNA expression positively correlated with the expression levels of gene sets involved in ribosomal function and with gene signatures predicting poor prognoses, which suggested that upregulation of TTF1 affected the prognosis of patients with HCC in accordance with elevated ribosomal activity. This is consistent with previous reports showing that increased ribosomal biogenesis predicts high-grade malig- 
nancy and poor prognosis $(22,23)$. Analysis of the GSEA database also suggested that there was a correlation between TTF1 expression and intrahepatic metastatic or recurrent signatures, which could explain the association with poor prognoses.

Finally, we found that $T T F 1$ overexpression resulted in upregulation of rRNA and promoted the proliferation of HCC cells in vitro. Activation of ribosome synthesis has been reported to be associated with tumor cell proliferation (24), and cancer cell proliferation affects clinical outcomes in patients with HCC (25). Although it should be noted that there exists many factors which are involved in the regulation of ribosomal activity (26) and it is necessary to examine the relation between TTF1 and such factors, our findings suggested that upregulation of TTF1 may have contributed to cancer progression through elevated ribosomal activity.

In conclusion, the present study showed that TTF1 expression was upregulated in tumor tissues from patients with HCC and that TTF1 mRNA levels were significantly associated with poor prognoses as an independent prognostic factor. Moreover, we showed that upregulation of TTF1 promoted the proliferation of HCC cells in vitro. The function of TTF1 was not fully elucidated, and further investigation would be needed to precisely determine the significance of TTF1, and thus it would be premature to predicate that TTF1 plays critical role in HCC. However, our results suggested that TTF1 may be a novel biomarker and may be a potential therapeutic target in $\mathrm{HCC}$.

\section{Acknowledgements}

The present study used the super-computing resource provided by the Human Genome Center at the Institute of Medical Science, University of Tokyo (http://sc.hgc.jp/shirokane.html). Clinical samples and corresponding clinical information were provided by the Oita Red Cross Hospital (Oita, Japan), the Hiroshima Red Cross Hospital and Atomic-bomb Survivors Hospital (Hiroshima, Japan), and the Iizuka Hospital (Fukuoka, Japan). We thank K. Oda, M. Kasagi, S. Kono, M. Aoyagi and T. Kawano for their excellent technical assistance. The present study was supported in part by the Funding Program for Next Generation World-Leading Researchers (LS094): Japan Society for the Promotion of Science Grant-in-Aid for Scientific Research (grant no. 24592005).

\section{References}

1. Jemal A, Bray F, Center MM, Ferlay J, Ward E and Forman D: Global cancer statistics. CA Cancer J Clin 61: 69-90, 2011.

2. Perz JF, Armstrong GL, Farrington LA, Hutin YJ and Bell BP: The contributions of hepatitis $B$ virus and hepatitis $C$ virus infections to cirrhosis and primary liver cancer worldwide. J Hepatol 45: 529-538, 2006.

3. Busch H, Byvoet P and Smetana K: The nucleolus of the cancer cell: A review. Cancer Res 23: 313-339, 1963.

4. Nguyen XT, Chan SM, Ngo TD, Raval A, Kim KK, Majeti R and Mitchell BS: Interaction of TIF-90 and filamin A in the regulation of rRNA synthesis in leukemic cells. Blood 124: 579-589, 2014.

5. Noller HF: Structure of ribosomal RNA. Annu Rev Biochem 53: 119-162, 1984

6. Arabi A, Wu S, Ridderstråle K, Bierhoff H, Shiue C, Fatyol K, Fahlén S, Hydbring P, Söderberg O, Grummt I, et al: c-Myc associates with ribosomal DNA and activates RNA polymerase I transcription. Nat Cell Biol 7: 303-310, 2005.
7. Grandori C, Gomez-Roman N, Felton-Edkins ZA, Ngouenet C, Galloway DA, Eisenman RN and White RJ: c-Myc binds to human ribosomal DNA and stimulates transcription of rRNA genes by RNA polymerase I. Nat Cell Biol 7: 311-318, 2005.

8. Grummt I and Pikaard CS: Epigenetic silencing of RNA polymerase I transcription. Nat Rev Mol Cell Biol 4: 641-649, 2003.

9. Lessard F, Morin F, Ivanchuk S, Langlois F, Stefanovsky V, Rutka $\mathrm{J}$ and Moss T: The ARF tumor suppressor controls ribosome biogenesis by regulating the RNA polymerase I transcription factor TTF-I. Mol Cell 38: 539-550, 2010.

10. Sander EE, Mason SW, Munz C and Grummt I: The aminoterminal domain of the transcription termination factor TTF-I causes protein oligomerization and inhibition of DNA binding. Nucleic Acids Res 24: 3677-3684, 1996

11. Evers R, Smid A, Rudloff U, Lottspeich F and Grummt I: Different domains of the murine RNA polymerase I-specific termination factor mTTF-I serve distinct functions in transcription termination. EMBO J 14: 1248-1256, 1995.

12. Kuhn A, Bartsch I and Grummt I: Specific interaction of the murine transcription termination factor TTF I with class-I RNA polymerases. Nature 344: 559-562, 1990.

13. Längst G, Blank TA, Becker PB and Grummt I: RNA polymerase I transcription on nucleosomal templates: The transcription termination factor TTF-I induces chromatin remodeling and relieves transcriptional repression. EMBO J 16: 760-768, 1997.

14. Lessard F, Stefanovsky V, Tremblay MG and Moss T: The cellular abundance of the essential transcription termination factor TTF-I regulates ribosome biogenesis and is determined by MDM2 ubiquitinylation. Nucleic Acids Res 40: 5357-5367, 2012.

15. Ruan Y, Sun L, Hao Y, Wang L, Xu J, Zhang W, Xie J, Guo L, Zhou L, Yun X, et al: Ribosomal RACK1 promotes chemoresistance and growth in human hepatocellular carcinoma. J Clin Invest 122: 2554-2566, 2012.

16. Subramanian A, Tamayo P, Mootha VK, Mukherjee S, Ebert BL, Gillette MA, Paulovich A, Pomeroy SL, Golub TR, Lander ES, et al: Gene set enrichment analysis: A knowledge-based approach for interpreting genome-wide expression profiles. Proc Natl Acad Sci USA 102: 15545-15550, 2005.

17. Roessler S, Jia HL, Budhu A, Forgues M, Ye QH, Lee JS, Thorgeirsson SS, Sun Z, Tang ZY, Qin LX, et al: A unique metastasis gene signature enables prediction of tumor relapse in early-stage hepatocellular carcinoma patients. Cancer Res 70: 10202-10212, 2010.

18. Wen F, Zhou R, Shen A, Choi A, Uribe D and Shi J: The tumor suppressive role of eIF3f and its function in translation inhibition and rRNA degradation. PLoS One 7: e34194, 2012.

19. Takada $H$ and Kurisaki A: Emerging roles of nucleolar and ribosomal proteins in cancer, development, and aging. Cell Mol Life Sci 72: 4015-4025, 2015.

20. Nakamura T, Rapp F and Busch H: Common features of the base composition of rapidly labeled RNA of nucleoli in a number of experimental tumors. Cancer Res 27: 1084-1091, 1967.

21. Albertson DG: Gene amplification in cancer. Trends Genet 22: 447-455, 2006.

22. Sirri V, Roussel P, Trerè D, Derenzini M and HernandezVerdun D: Amount variability of total and individual Ag-NOR proteins in cells stimulated to proliferate. J Histochem Cytochem 43: 887-893, 1995.

23. Tannapfel A, Geissler F, Köckerling F, Katalinic A, Hauss J and Wittekind C: Apoptosis and proliferation in relation to histopathological variables and prognosis in hepatocellular carcinoma. J Pathol 187: 439-445, 1999.

24. Torres-Montaner A, Bolivar J, Ortiz M and Valdivia MM: Immunohistochemical detection of ribosomal transcription factor UBF: Diagnostic value in malignant specimens. J Pathol 184: 77-82, 1998

25. Ito Y, Matsuura N, Sakon M, Takeda T, Umeshita K, Nagano H, Nakamori S, Dono K, Tsujimoto M, Nakahara M, et al: Both cell proliferation and apoptosis significantly predict shortened disease-free survival in hepatocellular carcinoma. Br J Cancer 81: 747-751, 1999.

26. Kusnadi EP, Hannan KM, Hicks RJ, Hannan RD, Pearson RB and Kang J: Regulation of rDNA transcription in response to growth factors, nutrients and energy. Gene 556: 27-34, 2015. 